\title{
REPLY
}

\section{REVEALING THE FACE OF ISIS}

\author{
J.L. Usó-Doménech and J. Nescolarde-Selva \\ Department of Applied Mathematics.University of Alicante. Alicante. Spain.
}

"Human ignorance does not stay behind the science grows as fast as this." (Jewish Proverb)

\begin{abstract}
This reply to Gash’s (Found Sci 2014) commentary on Nescolarde-Selva and Usó-Doménech (Found Sci $2013^{\mathrm{b}}$ ) answers the questions raised and at the same time opens up new questions.
\end{abstract}

Keywords: Existence, Indispensability Argument, Infinity, Reality, Truth, Universe of discourse

An old legend tells how in ancient Egypt, in the city of Thebes there was a temple to the goddess Isis in which was a statue of the deity with her face covered by a veil. One night, a young man quietly entered into the temple with the intention of lifting the veil from the face of the goddess. When he reached the sacred image, he lifted the veil and to his surprise there was a second veil. He continued and there was a third veil and so on, in a series that seemed endless. In the morning, the priests who guarded the temple entered, and were surprised and horrified to find the young man prostrate and plunged in deep madness. Consider this ancient legend as a metaphor, to answer some of the interesting issues raised by Professor Gash in his recent comment (Constructivism, Truth and Reality) to our paperReality, Systems and Impure Systems (Nescolarde-Selva and Usó-Doménech, 2013 ${ }^{\mathrm{b}}$ ).

About truth: The three terms Beauty, Goodness, Truth (kalon, agathou,aletheia) form a separate subgroup within the general family of Platonic transcendental ideas and their development can be considered separately. There are two rival truth theories: correspondence and coherence. For correspondence theory, truth is a relational property involving a specific relation to some portion of reality. For Russell (1912, 129): “Thus a belief is true when there is a corresponding fact, and is false when there is no corresponding fact". Bertrand Russell explained the correspondence theory elegantly and to sum up the theory, it simply states that a belief, statement, or proposition is true if and only if it corresponds with facts (Russell 1912, 119-130). For instance, the statement 'Russell wrote the Problems of Philosophy' is true if and only if it is indeed the case (a fact) that Russell wrote the Problems of Philosophy. Even though truthvalues apply to propositions and beliefs, it also depends on the objective world. A belief is false if a complex relation is not a fact. Russell's correspondence theory is considered to be a realist account because Russell argues that even though truth and falsity apply to beliefs and propositions, truth is still dependent on how reality really is. It depends on facts that are mind and language independent. For instance, the statement "Russell wrote the "Problems of Philosophy" is true if and only if it is indeed the case (a fact) that Russell wrote the "Problems of Philosophy" and that fact is independent of language and mind.

About cultural problems: Since Wittgenstein (1988) warns that it is possible to build logic from previously established axioms. An abstract belief level is formed by a set of 
elements called substantive beliefs forming the unquestionable truths of the system (axioms) and a set of derived beliefs, formed from substantive beliefs. Substantive beliefs constitute the axioms of the system, while many of the derived beliefs will constitute their theorems(Nescolarde-Selva and Usó-Doménech, 2013').If truth is a function of propositions and these, in turn, depend on the substantive beliefs, there will be as many "truths" as worldviews (Nescolarde-Selva and Usó-Doménech, 2013a), although many of them contradict empirical evidence ${ }^{1}$ and of course this can produce strong confrontations.

About Absolute and fragmented reality: What do we know about reality? Consider Physics: until the early twentieth century we assumed atoms were indivisible and the ultimate touchstone of matter. But no. It was found that they were formed with a core composed of protons and neutrons and with a series of orbiting electrons. Neither did the complexity stop just there. Most of these particles were in turn made up of quarks with strange properties such as color, flavor, charm, etc. And now, still moving to deeper explanations we have the superstring. Is this the end? We do not know.

Consider now the field of mathematical knowledge: For example, $D R$ logicism(Deductive Russellian logicism): R-logicism is true and there is a consistent, recursively axiomatizable and semantically complete theory of logic with all mathematical truths among its theorems. DR-logicism is known to be false. Gödel showed that the axiomatic simple-type theory embedded in Whitehead and Russell's Principia Mathematica (with the addition of an axiom of infinity) (1910) must, if it is consistent, be semantically incomplete. There are logical truths that are not deductive consequences of the axioms and inference rules (Landini, 2011). George Cantor initiated strong discussion when he promoted the view that there is more than one type of "infinity.". Until his time most mathematicians and philosophers had accepted Aristotle's view that infinity is a potentiality, a single abstraction, and not an actuality. Cantor (1955) radically broke with Aristotelian tradition by suggesting that infinity is an actuality, not a potentiality, and that it not only exists, but exists in multiple forms. His first distinction was between countable and uncountable infinities. Obviously, the number of elements in the set of all points on a line segment is also infinite. But are these two infinities of the same type? Not at all, said Cantor, because with the set of all integers we can count elements, but with the set of points on a line segment we cannot count the elements. So, if these infinities are different, should they be given different names? Cantor's answer was in the affirmative, and he began the process of naming different infinities by different Aleph numbers. Cantor's ideas that there were infinite more infinite than others, in addition to leading to scandal led to the formalization and extension of certain concepts such as cardinality and ordinal. We will not delve into these concepts as they are well known. We just point out that cardinal indicates

\footnotetext{
${ }^{1}$ An current example: Saleh Al-Fawzan, member of the Saudi Council of Senior Scholars, recently stated in a televised interview that not only the Earth does not rotate around the sun, the opposite is true. Proof of Al-Fawzan for this assertion that the sun revolved around the earth is none other than the Qur'an. The interview was broad cast on Saudi Channel 1 and translated by the Institute of Media Research Middle East (MEMRI). In the interview, the presenter asks Al-Fawzan, "Allah says in one verse of the Qur'an: "And the sun goes toward its stopping point. That is the determination of the All-Mighty, the AllKnowing». "So the Sun rotates around the earth?" Saleh Al-Fawzan responds by saying: "There is no doubt about it. The Quran says: "The sun runs ..." However, they say that he sun is in place and the earth moves. This contradicts the Qur'an." He adds, "To ignore the Qur'an and adopt modern theories is not something a Muslim can do. A Muslim should follow the Qur'an."
} 
unordered set size that is, ignoring order. The set of natural numbers Cantor named as $\aleph_{0}$.The upper power of c will be $c_{1}$ or $\aleph_{2}$ cardinal corresponding to the set of functions of a real variable, which is set of, and the definition is, for example[0,1], is such that $\aleph_{2}=2^{c}$, i.e., has the same cardinal value as the set of continuous parts. If the functions are continuous, then the power of the continuum that form is c or $\aleph_{2}$. According to Fischbein et al. (1979) the world of $\aleph_{0}, \aleph_{1}, \aleph_{2}, \ldots$ composed of actual infinites represents a potential, not an actual form of infinity. This makes us think that the perceived or conceived reality, is not only fragmented, but seems to be like an onion with many layers or like a Russian Matriuska where we do not know where its end is, if it exists. But there are more difficulties: contradictions between actual and potential infinity, between completed and potential infinity, between addition and accretion, and between abstract and concrete (See Oppy, 2006). Looks like not only would we have fragmentation and hierarchy here but both logic of paraconsistency and of coincidentia oppositorum govern in what we consider reality.

About Indispensability Argument: The Quine-Putnam mathematical indispensability argument (Putman, 1971, 1979; Quine, 1953, 1955, 1963, 1981; Quine and Ullian, 1970) asserts that mathematical entities are on par with other scientific entities from our best scientific theories. This argument is an argument for mathematical realism. Mathematical entities exist because they are indispensable in our best scientific theories. Without them, our best scientific theories would be false (Castro, 2013).The indispensability argument, in its most general form, alleges that our knowledge of mathematics is justified by our knowledge of empirical science. Quine’s argument is the following:

(QI) QI.1: We should believe the theory which best accounts for our empirical experience.

QI.2: If we believe a theory, we must believe in its ontic commitments.

QI.3: The ontic commitments of any theory are the objects over which that first-order theory quantifies.

QI.4: The theory which best accounts for our empirical experience quantifies mathematical objects.

QI.C: We should believe that mathematical objects exist.

Putman's argument is following:

(PI) PI.1: We have intuitions about the truth of mathematical statements, and of combinatorial facts.

PI.2: These intuitions are justified quasi-empirically.

PI.3: Quasi-empirical justifications yield truth.

PI.C: So, mathematical statements are true, and justified.

Putnam's success argument for mathematics is analogous to, and may be compared with, his success argument for scientific realism, which we will discuss briefly and then set aside. The scientific success argument relies on the claim that any position other than realism makes the success of science miraculous.

(SS) SS.1: Scientific theory is successful.

SS.2: There must be a reason for the success of science.

SS.3: No positions other than realism in science provide a reason.

SS.C: So, realism in science must be correct.

Given the relatively uncontroversial SS.1 and SS.2, the argument for realism in science rests on SS.3, and the miracles argument. But, strictly false theories such as Newtonian mechanics can be extremely useful and successful. If realism were the only 
interpretation which accounted for the success of science, then the utility of many false scientific theories is left unexplained. An instrumentalist interpretation on which theories may be useful without being true accounts more adequately for the utility of false theories.

There are probably good responses to this quick criticism, but refuting SS is beside the point, here. Our point is essentially that the miracles argument is best understood as an argument for scientific realism, and not for mathematical realism. We now set it aside and examine Putnam's analogous but independent success argument for mathematics.

(MS) MS.1: Mathematics succeeds as the language of science.

MS.2: There must be a reason for the success of mathematics as the language of science.

MS.3: No positions other than realism in mathematics provide a reason.

MS.C: So, realism in mathematics must be correct.

Argument Q-P (Quine\&Putman)

(1Q-P) Our best scientific theory of the world makes indispensable use of scientific things. (This is taken as an unvarnished fact.)

(2Q-P) To draw a testable consequence from our theory requires the use of various far flung parts of that theory, including much mathematics, so the confirmation resulting from a successful test adheres not to individual statements but to large bodies of theory. (This is confirmational holism².)

(3Q-P) Our theory is committed to those things that one says 'there are'. (This is Quine's criterion of ontological commitment ${ }^{3}$.)

(;) Our theory, and we who adopt it, are committed to the existence of scientific things.

Experience gives the status of knowledge of the physical world to the rational construction. But, experience alone would not in any way guarantee the rationality of the construction itself. Empiricism and perception are, in principle, devoid of any mathematical rights.

\footnotetext{
${ }^{2}$ Confirmational holism is a view that is extremely important to the empiricist movement. Confirmational holism states that when a hypothesis is proven by empirical means, then all underlying theories that correspond to that hypothesis are also proven. This is extremely important in regards to furthering our understanding of the world. Philosophy can easily get hung up or hit a stopping block as a result of instances such as mathematical theory being based on previous mathematical theory. It would seem that an almost endless series of proofs must be confirmed in order to even get to any hypothesis that is based on empirical findings. However, confirmational holism allows hypotheses as a whole to be verified by finding them in nature (Bueno, 2003). Furthermore, confirmational holism takes naturalism one step further. Naturalism in short is a scientific process of observing nature. From this scientific process, a person can be more certain of asserting statements about the world. However, naturalism on its own does not truly confirm anything. This is where confirmational holism steps up and takes over. If naturalism can formulate a statement that is more probable then not, and there are mathematical hypotheses that coincide with this statement, then everything is confirmed (Colyvan, 2003).
}

${ }^{3}$ In the philosophy of language and metaphysics, an ontological commitment is said to be necessary in order to make a proposition in which the existence of one thing is presupposed or implied by asserting the existence of another. We are "committed" to the existence of the second thing, even though we may not have expected it, and may have intended to assert only the existence of the first. The kind of secondary entities in question are typically abstract objects such as universals, sets, classes, or fictional objects (Audi, 1999). 
However, for nominalists, there are no such things as mathematical entities, these entities are abstract entities, and abstract entities simply do not exist. And this leads us to the problem of existence.

About existence: There is a fairly widespread belief that the problem of existence is not an essential issue for logic. However, the logical problem of existence and how to treat and resolve it completely differs from the corresponding metaphysical problem.

From the historical point of view, the decisive attempt to solve this problem for symbolic logic is due to Russell, who developed it especially in his theory of description. However, by including extra logical considerations into the formal treatment of the problem, Russell's exposition is unnecessarily complicated, losing the universality that is expected of a formal science. Consider Russell's phrase "The king who now governs France is bald". This proposition was considered a false ostensive $(\mathrm{O})^{4}$, not because the King of France has hair, but because the king who governs now France does not exist. For an ostensive proposition to be true, it is necessary that the respective subject exists and also corresponds predicate. Logic, though formal, must deal with the problem of existence. However, logic should be limited to talking about "formal existence" or the "existence on a formal system. "That something, which formally exists, is also really there, and this does not depend on formal logic, but on epistemology, that is, what is understood by "real" and if there is a real correspondence to the system given . At a higher system of functions we distinguish: individuals, classes of individuals, relations between individuals, and classes of classes of individuals, etc. "There are some ....or There is ...." can be formally defined in these systems from the words "no", "or", and "all", for both the individual and classes. Then we can deduce that formal existence is nothing other than belonging to the universe of discourse ${ }^{5}$, where

\footnotetext{
${ }^{4}$ Ostensive definition (Russell, 1984) is the process by which an individual receives instruction to understand a lexeme in a different way than through the use of other lexemes. The ostensibility of a sender is in inverse proportion to the quantity of information being provided by a particular language. An ostensive definition conveys meaning using examples. In this case a Sender refers to an absolute being or referent (Ogden and Richards, 1989), also known as designatum (Carnap, 1942). In this case the information about the referent is in the foreground. The language in this situation is called an ostensive function $\left(O_{F}\right)$, because the proposition is the translation of an ostension, equivalent to a remark. When the Subject makes a proposition or set of ostensive propositions Subject is operating on Reality. We must remember that for the Subject reality is processed with a system of signs encoded in language. Both signs and language are heterologous systems or related ways of representing reality. We call ostensive those lexemes that function as verbal pointers to references external to the sender that may be real or unreal. These minimal units of significance require an address to a reference that the sender locates outside himself. In our theory we will divide propositions into ostentives and estimatives. An ostensive proposition ( $\mathbf{O})$ is one in which the sender specifies connotations that apply to the reference, i.e., the nature of the qualitative and quantitative apprehension of reality that at that moment constitutes a referent.
}

\footnotetext{
${ }^{5}$ The universe of discourse (or simply universe), is the set of entities over which certain variables of interest in some formal treatment may range. The universe of discourse is usually identified in the preliminaries, so that there is no need in further treatment to specify each time the range of the relevant variables (Corcoran, 1995, 941). For Boole in every discourse, whether of the mind conversing with its own thoughts or of the individual in his intercourse with others, there is an assumed or expressed limit within which the subjects of its operation are confined. The most unfettered discourse is that in which the words we use are understood in the widest possible application, and for them the limits of discourse are co-extensive with those of the universe itself. But more usually we confine ourselves to a less spacious field.
} 
the so-called universe of discourse is the collection of individuals, i.e., values that meet or do not meet any function (of the first order) of the system. The universe of discourse is not absolute and given in advance. On the contrary, if we apply symbolic logic to any field of science, a belief system or daily life problems, we define a universe of discourse. This definition is arbitrary, provided that the following conditions are satisfied:

1) The universe of discourse has at least one element ${ }^{6}$.

2) That there are not in the universe of discourse elements in different orders, such as individuals or sets ${ }^{7}$.

Once these two conditions are met, there is absolute freedom. We might consider, for example, implemented a system where the universe of discourse is defined as soccer teams. The practical value of this system would be very small, because it could not deal with a problem that does not relate directly to soccer clubs. In this case, only soccer clubs exist. However, there is nothing exceptional in working with a very limited universe of discourse. This is often done in mathematics, where the universe of discourse is restricted, for example to natural numbers or points in the plane. Then there are just the natural numbers or points in the plane. Then, and as said above, "formally exists" (denoted as $\exists_{F}$ ) acquires a relative. What exists for a system or a system application, is not necessarily the case for another. Usually the universe of discourse of technology is formed so that it is not perpetually changing. However, there could be a fantastic technological universe of discourse that includes perpetual motion; for this other system, there is perpetual change. For the same reason, in an investigation into the mythological animals, both the unicorn and Pegasus exist, contrary to common usage in biological research. The relativization of existence is surprising only if we attribute an absolute character to the word "exist" in common language. Now there are sentences that use "exist" in the sense: "This person does not exist for me," where there is formed a universe of discourse that excludes this particular individual. Usually, however, the term "exist" is used with an absolute and general sense. But at the moment we want to point out that, problems arise distinguishing between "really exist", and "exist in the consciousness of man," etc. Each of these terms is itself a source of new discussions ${ }^{8}$, often characterized by obscurity and confusion. Traditional logic does not speak of the universe of discourse ${ }^{9}$. But it is possible find indications in in the following examples,

${ }^{6}$ Starting from an axiomatization, we can work with universes of discourse without a single element.

\begin{abstract}
${ }^{7}$ This condition is due to type theory. A type theory is any of a class of formal systems, some of which can serve as alternatives to set theory as a foundation for all mathematics. In type theory, every "term" has a "type" and operations are restricted to terms of a certain type. In a system of type theory, each term has a type and operations are restricted to terms of a certain type. A typing judgment M: A describes that the term $\mathrm{M}$ has type $\mathrm{A}$. For example, nat may be a type representing the natural numbers and $0,1,2, \ldots$ may be inhabitants of that type. The judgment that 2 has type nat is written as 2:nat. A function in type theory is denoted with an arrow $\rightarrow$. The function addOne(commonly called successor), has the judgment addOne: nat $\rightarrow$ nat. Calling or "applying" a function to an argument is usually written without parentheses, so addOne 2 instead of addOne(2).
\end{abstract}

${ }^{8}$ For example: Is there really an electromagnetic field and potential energy?

${ }^{9}$ In seeking formal determinations for "exist", we expect to find them, for example, in formulations like "have their own essence." 
which allow giving a negative answer to the question. The universe of discourse of these examples includes what really exists (a physicalistic sense ${ }^{10}$ ) and also, spirit, justice, love, resignation, etc; but not Pegasus, centaurs, fairies or dragons. The two crucial questions are:

1) Who decides this and what are the criteria?

2) Will what really will exist with some probability be included in the universe of discourse?

In the affirmative case, the Siamese twin brothers who could be born on 1 January 2100 would be included. If not, the next solar eclipse will be excluded. What and where is the limit? From a formal point of view, no universe of discourse is given in advance; anyone universe of discourse that satisfies the necessary conditions can be used. The extended epistemological belief that there is a universe of discourse defined rigorously, that would be true and should be "the universe of discourse of logic", cannot be justified, as we have seen.

\section{REFERENCES}

Audi, R. (Ed). 1999. Ontological commitment. The Cambridge Dictionary of Philosophy (Paperback 2nd ed.). p. 631.

Bueno, O. 2003.Application of Mathematics and Under determination in Claudio Delrieux and Javier Legris (eds.), Computer Modeling of Scientific Reasoning. (Bahia Blanca: Ediuns).

Castro, E. 2013.Defending the Indispensability Argument: Atoms, Infinity and the Continuum. J. Gen Philos. Sci. 44. Pp 41-61.

Cantor, G. 1955. Contributions to the Founding of the Theory of Transfinite Numbers. (Transladt and provided with an introduction and notes by Philip E.B. Jourdain). Open Court Publishing. La Salle II.

Carnap, R. 1942. Introduction to Semantics.Cambridge. Mass.

Colyvan, M. 2003. Indispensability Arguments in the Philosophy of Mathematics. The Stanford Encyclopedia of Philosophy (Fall 2003 Edition), Edward N. Zalta (ed.), URL=http://plato.stanford.edu/archives/fall2003/entries/mathphil-indis.

Corcoran, J. 1995. Universe of discourse. Cambridge Dictionary of Philosophy, Cambridge University Press.

\footnotetext{
${ }^{10} \mathrm{Physicalism}$ is the thesis that everything is physical or as contemporary philosophers sometimes put it, that everything supervenes on, or is necessitated by, the physical. The thesis is usually intended as a metaphysical thesis, parallel to the thesis attributed to the ancient Greek philosopher Thales, that everything is water, or the idealism of the 18th Century philosopher Berkeley, that everything is mental. The general idea is that the nature of the actual world (i.e. the universe and everything in it) conforms to a certain condition, the condition of being physical. Of course, physicalists don't deny that the world might contain many items that at first glance don't seem physical - items of a biological, or psychological, or moral, or social nature. But they insist nevertheless that at the end of the day such items are either physical or supervene on the physical.
} 
Fischbein, E,Tirosh, D. and Hess, P. 1979. The intuition of Infinity. Educational Studies in Mathematics.10, pp 3-40.

Gash, H. 2014. Constructivism, truth and reality. Foundations of Science. Online first.

Landini, G. 2011. Logicism and the Problem of Infinity: The Number of Numbers. Philosophia Mathematica. (III), 19. pp 167-212.

Nescolarde-Selva, J. and Usó-Domènech, J. L. 2013 . Semiotic Vision of Ideologies. Foundations of Science. DOI 10.1007/s10699-013-9329-9.

Nescolarde-Selva, J. A. and Usó-Doménech, J. L. 2013 ${ }^{\mathrm{b}}$ Reality, System and Impure Systems. Foundations of Science. Online First.

Nescolarde-Selva, J. and Usó-Doménech, J. L. 2013‥Topological Structures of Complex Belief Systems. Complexity. DOI: 10.1002/cplx.21455. Vol 19, 1.46-62.

Ogden, C.K. and Richard, I.A. 1989, The Meaning of Meaning. With a new introduction by Umberto Eco. Harcourt Brace Jovanovich, Publishers, Orlando. Florida.

Oppy, Gr. 2006. Philosophical Perspectives of Infinity. Cambridge University Press. Cambridge.

Putnam, Hilary. 1956. Mathematics and the Existence of Abstract Entities. Philosophical Studies 7: 81-88.

Putnam, H. 1971. Philosophy of logic. In S. Laurence \& L. Macdonald (Eds.), Contemporary readings in foundations of metaphysics (pp. 404-434). Oxford: Blackwell.

Putnam, H. 1979. What is mathematical truth? In Mathematics, matter and method: Philosophical papers vol. I (pp. 60-78). Cambridge: Cambridge University Press.

Quine, W. V. 1953. From a logical point of view. Cambridge, MA: Harvard University Press.

Quine, W. V. 1955. Posits and reality. In The ways of paradox and other essays (pp. 233-241). New York: Random House.

Quine, W. V. 1963. Carnap and logical truth. In P. Benacerraf \& H. Putnam (Eds.), Philosophy of mathematics selected readings (pp. 355-376). Cambridge: Cambridge University Press.

Quine, W. V. 1981 a Success and limits of mathematization. In Theories and things. Cambridge, MA: Harvard University Press.

Quine, W. V., \& Ullian, J. 1970. The web of belief. New York: Random House. 
Resnik, M. 1997. Mathematics as a science of patterns. Oxford: Oxford University

Russell, B. 1912, Problems of Philosophy. Reprinted at Oxford: Oxford University Press 1971.

Russell, B. 1984. El conocimiento humano. Trans: Nestor Míguez. Orbis-Hyspamérica. España.(In Spanish).

Whitehead, Alfred North, and Bertrand Russell [1910]. Principia Mathematica. vol. 1 (1910), vol. 2 (1911), vol. 3 (1912). Cambridge: Cambridge University Press. 2nd ed. 1957.

Wittgenstein, L. 1988. Sobre la certeza. Barcelona: Gedisa. (In Spanish).

Wittgenstein, L. 2001. Tractatuslogico-philosophicus, trad. Gilles-Gaston Granger: Gallimard, Paris. (In French). 